\title{
Anestesia en paciente pediátrico con Síndrome de Treacher Collins
}

\author{
*Walter Delgado-Maidana ${ }^{1}$, $* *$ Raúl Eduardo Alonso $^{1}(* * *$ Ana Claudia De Barros- \\ Barreto Mazó ${ }^{1}$ \\ ${ }^{1}$ Universidad Nacional de Asunción, Facultad de Ciencias Medicas, Hospital de Clínicas, Departamento \\ Central de Anestesiología. Paraguay
}

Cómo referenciar este artículo/ How to reference this article:

\begin{abstract}
Delgado-Maidana W, Alonso RE, De BarrosBarreto Mazó AC. Anestesia en paciente pediátrico con Síndrome de Treacher Collins. Mem. Inst. Investig. Cienc. Salud. 2020; 18(3): $67-72$
\end{abstract}

\section{RE S U M E N}

El Síndrome de Treacher Collins (STC) constituye un reto para el anestesiólogo por malformaciones craneofaciales que complican el manejo de su vía aérea e intubación. Presentamos el caso de una paciente ( 8 años) con diagnóstico de STC que debía someterse a una cirugía de colocación de implante de conducción ósea bajo anestesia general. Presentaba un antecedente de intubación difícil, marcada micrognatia y distancia tiromentoniana de $2 \mathrm{~cm}$. Se planteó un esquema de intubación en dos etapas secuenciales. En la primera etapa se realizó una evaluación de la vía aérea (visualización de la glotis) bajo sedación con dexmedetomidina, remifentanilo y propofol. Al visualizar la glotis se pasó a la segunda etapa para realizar la intubación posterior a la inducción anestésica.El manejo exitoso se fundamentó en una sedación adecuada y la utilización de un videolaringoscopio con pala curva para la evaluación previa de la vía aérea y posterior intubación sin complicaciones.

Palabras clave: Vía aérea difícil, Treacher Collins, anestesia, video laringoscopía.

\section{Anesthesia in a pediatric patient withTreacher Collins Syndrome}

\section{ABSTRACT}

Treacher Collins Syndrome (TCS) constitutes a challenge for the anesthesiologist due to craniofacial malformations that make management of the airway and intubation difficult. We present a case of a patient (8-year-old) diagnosed with TCS who had to undergo surgery for the placement of a bone conduction implant under general anesthesia. She had a history of difficult intubation, marked micrognathia and a thyromental distance of $2 \mathrm{~cm}$. An intubation scheme in two sequential stages was proposed. In the first stage, an evaluation of the airway (visualization of the glottis) was carried out under sedation with dexmedetomidine, remifentanil and propofol. When the glottis was visualized, we proceeded to the second stage to carry out intubation after anesthetic induction. The successful management of this case was based on adequate sedation and the use of a video laryngoscope with a curved blade for prior evaluation of the airway and subsequent intubation without complications.

Keywords: Difficult airway, Treacher Collins, anesthesia, pediatrics, video laryngoscope.

\footnotetext{
Auxiliar de La enseñanza

${ }^{2}$ Residente de Anestesiología

${ }^{3}$ Residente de Anestesiología
} 


\section{Anestesia em paciente pediátrico com Síndrome de Treacher Collins}

\section{RESUMO}

A síndrome de Treacher Collins (STC) constitui um desafio para o anestesiologista devido às malformações craniofaciais que dificultam o manejo da via aérea e a intubação. Apresentamos o caso de uma paciente ( 8 anos) com diagnóstico de STC que foi submetida a uma cirurgia para colocação de implante de condução óssea sob anestesia geral. Ela tinha história de intubação difícil, micrognatia acentuada e distância tiromentoniana de $2 \mathrm{~cm}$. Foi proposto um esquema de intubação em duas etapas sequenciais. Na primeira etapa, foi realizada avaliação das vias aéreas (visualização da glote) sob sedação com dexmedetomidina, remifentanil e propofol. Quando a glote foi visualizada, a segunda etapa foi realizada para realização da intubação após a indução anestésica.

O manejo bem-sucedido baseou-se na sedação adequada e no uso de videolaringoscópio com lâmina curva para avaliação prévia da via aérea e posterior intubação sem complicações.

Palavras-chave: Via aérea difícil, Treacher Collins, anestesia, videolaringoscopia.

\section{INTRODUCCIÓN}

El síndrome de Treacher Collins (STC) es una enfermedad hereditaria rara causada por una mutación del gen TCOF1 ubicado en el cromosoma 5. También se la denomina Franceschetti-Zwahlen-Klein o disostosis mandibulofacial. Afecta a 1 de cada 50000 recién nacidos y se caracteriza por la presencia de anomalías en el desarrollo morfológico del cráneo y la cara ${ }^{(1,2)}$.

En el STC están presentes con mucha frecuencia anomalías bilaterales simétricas de las estructuras del primer y segundo arco branquial, debido a hipoplasia (desarrollo incompleto o defectuoso) de ciertas porciones del cráneo, bordes supraorbitales y arcos zigomáticos. Además se presentan malformaciones craneofaciales, como labio y paladar hendido, ausencia o malformación de pabellones auriculares y conductos auditivos, pérdida de la audición, hipoplasia malar y maxilar y anomalías en las uniones temporo-mandibulares ${ }^{(2-5)}$.

Una vía aérea difícil (VAD) se presenta cuando un experto puede encontrar dificultad en la ventilación con máscara facial y/o en la intubación traqueal de un paciente. Esta situación puede ser predecible o impredecible ${ }^{(6,7)}$. En el caso del STC, las alteraciones cráneo faciales son indicadores de una vía aérea difícil, lo que supone una situación predecible.

Las VAD previstas permiten planificar el manejo anestesiológico a fin de evitar complicaciones que pudieran llegar a ser catastrófica, como por ejemplo una situación de "no ventilación, no intubación".

Existen varias alternativas para manejo adecuado de una VAD y cuyo objetivo principal es mantener la oxigenación adecuada en el paciente ${ }^{(6)}$.

En el paciente adulto se plantea realizar la intubación con el paciente vigil ${ }^{(8)}$, para lo cual se necesita la colaboración del paciente, situación muy poco probable en un paciente pediátrico.

Considerando las alteraciones morfólogicas craneofaciales en el paciente pediátrico con STC, el principal desafío para el anestesiólogo constituye el manejo de la vía aérea.

Presentamos un caso de una paciente con diagnóstico de STC y en planes de una anestesia general para una cirugía de colocación de un implante de conducción ósea para la audición.

\section{CASO CLÍNICO}

Se presenta al servicio de Anestesiología del Hospital de Clínicas una paciente de sexo femenino, 8 años, $18,3 \mathrm{~kg}$ y $1,25 \mathrm{~m}$ con los siguientes diagnósticos: Sx de Treacher Collins, agenesia del conducto auditivo externo bilateral e hipoacusia 
conductiva moderada bilateral. El plan quirúrgico fue la colocación de un implante de conducción ósea.

Como antecedentes remotos, el embarazo de madre llegó a término y sin complicaciones, el parto fue vaginal y requirió oxigenoterapia e incubadora al nacer. Permaneció internada por casi un mes para estudios debido a rasgos sindrómicos no previstos. Fue alimentada por sonda durante los primeros meses de vida debido a la ausencia de reflejo de succión y la presencia de paladar hendido.

Al mes de vida fue diagnosticada con el síndrome de Treacher Collins. Presentó convulsiones los tres primeros meses de vida. A los 2 años fue intervenida quirúrgicamente en otro centro para reparación de la fisura palatina donde la madre refiere antecedentes de intubación difícil y posterior estadía en terapia intensiva por edema de glotis que impidió su extubación al finalizar el procedimiento.

Actualmente presenta una alteración a nivel de lenguaje expresivo y dificultad a nivel de percepción auditiva y de integración fonética. Además presenta disglosia e hipernasalidad derivados de factores morfológicos.

Se realizó la evaluación preanestésica centrada en la evaluación de la vía aérea en donde resaltaba la marcada micrognatia con una distancia tiromentoniada de $2 \mathrm{~cm}$. Esta condición sumada al antecedente hicieron prever el caso como una vía aérea difícil prevista.

Teniendo en cuenta la patología de base y los antecedentes referidos por la madre se planteó el siguiente esquema de intubación en 2 etapas secuenciales:

- Etapa 1: sedación sin depresión respiratoria (carga con dexmedetomidina $0,4 \mu \mathrm{g} / \mathrm{kp}+$ remifentanilo $0,1 \mu \mathrm{g} / \mathrm{kp} / \mathrm{min}+$ anestesia local tópica con lidocaína en spray \pm propofol según necesidad). Evaluación de la visualización de la glotis con el video laringoscopio C-MAC® S D-blade

- Etapa 2: Intubación orotraqueal con el videolaringoscopio o con fibrobroncoscopio flexible según visualización previa.

Se explicó el plan de procedimiento a los padres y se interactuó con la niña para ganar su confianza previa a la cirugía y poder obtener su colaboración.
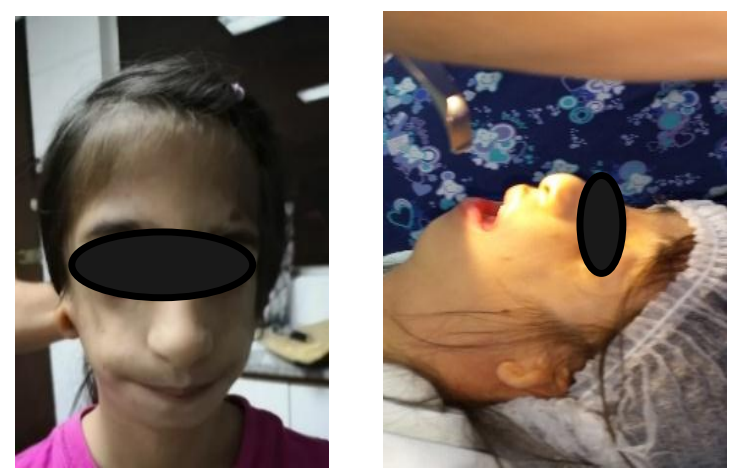

El día de la cirugía, ingresó a quirófano sin sedación previa, se administró oxigeno por cánula nasal ( $2 \mathrm{l} / \mathrm{min})$, se monitorizó a la paciente observándose signos vitales en rango.

Etapa 1. Contando con la buena predisposición de la niña se le realizó una vía periférica con punzocath no 22 y la administración de fármacos.

Minuto 0: se inició infusión con $8 \mu \mathrm{g}$ de dexmedetomidina para 10 minutos.

Minuto 5: inicio de infusión de remifentanilo a $0,1 \mu \mathrm{g} / \mathrm{kp} / \mathrm{min}$.

- Minuto 8: se introdujo ligeramente la pala del videolaringoscopio para realizar una instilación de lidocaína en spray en la orofaringe.

- Minuto 10: 0,2 mg de atropina + $20 \mathrm{mg}$ de propofol mezclado con $20 \mathrm{mg}$ de lidocaína.

- Minuto 11: se realizó la evaluación con el videolaringoscopio manteniendo la respiración espontánea. 
A pesar de observarse muy anterior, se evidenció la glotis y las cuerdas vocales (grado 2 de Cormack-Lehane). Durante la introducción del videolaringoscopio llamó la atención la presencia de una solución de continuidad del paladar duro, remanente de la cirugía de paladar hendido pasada.

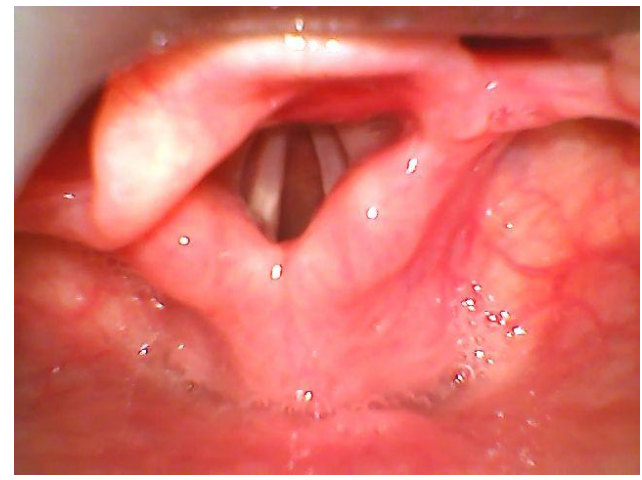

Etapa 2. Debido a la evaluación descripta, se decide realizar la intubación con el video

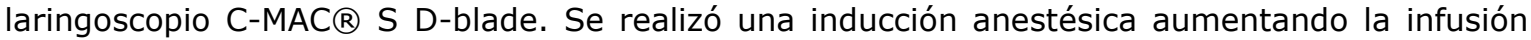
de remifentanilo a $0,2 \mu \mathrm{g} / \mathrm{kp} / \mathrm{min}$, se administraron $25 \mathrm{mg}$ más de propofol y $10 \mathrm{mg}$ de atracurio. Se ventiló a la paciente sin dificultad. Posteriormente se procedió a intubarcon éxito a la paciente en el primer intento ayudado por una ligera maniobra de BURP. Se utilizó un tubo endotraqueal $n^{\circ} 5,5$ montado sobre un estilete semirrígido.

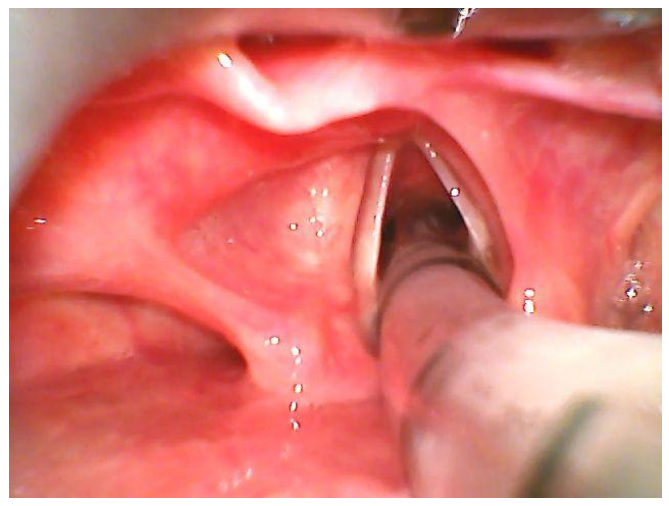

Se realizó el mantenimiento con una $\mathrm{FiO}_{2}$ de 0.5 , sevoflurano a $2 \%$ y remifentanilo a $0,25 \mu \mathrm{g} / \mathrm{kp} / \mathrm{min}$. Se administraron $500 \mathrm{mg}$ de dipirona, $5 \mathrm{mg}$ de ketamina y $4 \mathrm{mg}$ de dexametasona previo al estímulo quirúrgico.

La cirugía duró 3 horas. Se administraron $3 \mathrm{mg}$ de ondansetrón y se realizó la extubación de la paciente a los 10 minutos de culminada la cirugía. La paciente pasó a sala de recuperación post anestésica sin complicaciones.

\section{DISCUSIÓN}

EI STC constituye un reto para el anestesiólogo por las malformaciones craneofaciales que hacen complicado el manejo de su vía aérea y la intubación. Considerando las características propias de un paciente pediátrico este reto aumenta por la reserva pulmonar limitada y un alto riesgo de obstrucción de la vía aérea superior ${ }^{(3)}$.

Los dispositivos supraglóticos, fibrobroncoscopios y el videolaringoscopio son herramientas útiles para el manejo de la $\operatorname{VAD}{ }^{(9,11,12)}$. Los videolaringoscopios con hojas curvas tipo D-Blade ${ }^{\circledR}$ tienen como ventaja que no necesitan una curva de aprendizaje importante para manejarlo con practicidad y tienen una buena efectividad ${ }^{(13)}$.

En una VAD de un paciente adulto se recomienda la técnica de intubación vigil con fibroscopía, preservando la ventilación espontánea para evitar cualquier situación en la cual no se pueda oxigenar al paciente. Esta técnica es de aplicación casi imposible 
en un paciente pediátrico ya se necesita la colaboración del paciente y pueden existir molestias desagradables que un niño no podría tolerar.

En el caso presentado se aseguró una planificación previa con una evaluación preoperatoria minuciosa, durante la cual se aprovechó para una interacción previa del anestesiólogo con la paciente. Este hecho fue fundamental, ya que se ganó la confianza de la niña y esto ayudó a que ingresara al quirófano tranquilamente y permita la canalización de la vía periférica.

En una VAD se recomienda mantener la respiración espontánea hasta tanto el anestesiólogo esté seguro qué podrá intubar al paciente ${ }^{(6,11)}$. Teniendo en cuenta dicha premisa, se planificó en la primera etapa una evaluación previa de la vía aérea (visualización de la glotis) bajo visión directa con videolaringoscopía y con la paciente bajo los efectos de una sedación confortable, sin pérdida de la respiración espontánea.

Al obtener una visualización adecuada y fácil de la glotis se consideró probable la intubación con el mismo instrumento, en este caso el videolaringoscopio, y se pasó a la etapa 2 para realizar la intubación posterior a la inducción anestésica.

La selección adecuada de los fármacos fue muy importante para garantizar la sedación adecuada del paciente durante la etapa 1 . La dexmedetomidina ${ }^{(13,14)}$ tiene la ventaja de no deprimir la respiración, y con su efecto sedante - analgésico favoreció la disminución de dosis de los demás fármacos utilizados: remifentanilo y propofol.

El manejo exitoso de este caso se fundamentó en una sedación adecuada para la evaluación previa de la vía aérea y la utilización de un videolaringoscopio con pala curva que hizo posible un procedimiento sencillo y efectivo en un paciente complejo. La visualización previa adecuada garantizó la intubación posterior sin complicaciones.

\section{Conflicto de intereses}

Los autores declaran no tener ningún conflicto de intereses.

Fuente de financiación: No se contó con ninguna financiación externa. Se utilizaron recursos propios aportados por los investigadores.

\section{REFERENCIAS BIBLIOGRAFICAS}

1. Srinath S. Treacher Collins syndrome. J Pharm Sci Res. 2014; 6(6):247-50.

2. Guzmán DA, Reyes B, Quiroga SC. Revisión bibliográfica sobre síndrome de Treacher Collins. Rev Chil Anest. 2019; $48(2): 123-8$

3. Dauwerse JG, Dixon J, Seland S, Ruivenkamp CAL, Van Haeringen $A$, Hoefsloot $\mathrm{LH}$, et al. Mutations in genes encoding subunits of RNA polymerases $i$ and III cause Treacher Collins syndrome. Nat Genet. 2011; 43(1):20-2.

4. Hosking J, Zoanetti D, Carlyle A, Anderson $P$, Costi $D$. Anesthesia for Treacher Collins syndrome: A review of airway management in 240 pediatric cases. Paediatr Anaesth. 2012; 22(8):752-8.

5. Aljerian A, Gilardino MS. Treacher Collins Syndrome. Clin Plast Surg [Internet]. 2019; 46(2):197-205. Available from: https://doi.org/10.1016/j.cps.2018.11.00 5

6. Edelman D, Perkins $E$, Brewster D. Difficult airway management algorithms: a directed review. Anaesthesia 2019, 74, 1175-85

7. Galván-Talamantes Y, Espinoza de los Monteros-Estrada I. Manejo de vía aérea difícil. Rev Mex Anestesiol. 2013; 36(SUPPL.1):312-5.

8. Wilson WM, Smith AF. The emerging role of awake videolaryngoscopy in airway management. Anaesthesia 2018;73: 1058-61

9. Golinko MS, LeBlanc EM, Hallett AM, Alperovich $M$, Flores $R L$. Long-term surgical and speech outcomes following palatoplasty in patients with treachercollins syndrome. J Craniofac Surg. 2016; 27(6):1408-11.

10. Sethi D. Airway management in a child with Treacher Collins syndrome using CMAC videolaryngoscope. Anaesth Crit Care Pain Med [Internet]. 2016; 35(1):67-8. Available from: http://dx.doi.org/10.1016/j.accpm.2015. 06.011

11. Uesugi T. Evaluation of the Dams TuLip$\mathrm{i}^{\mathrm{TM}}$ : a new airway device for flexible bronchoscopic intubation. Can J Anesth [Internet]. 2019; 66(8):993-4. Available from: https://doi.org/10.1007/s12630019-01384-X

12. Niwa $Y$, Takeuchi M. Dams TuLip- $i^{\mathrm{TM}}$ is a useful device for performing fiberscopyguided orotracheal intubation in a patient 
Delgado-Maidana, et al Anestesia en paciente pediátrico con Síndrome de Treacher Collins...

with Treacher Collins syndrome. J Clin Anesth. 2019; 56(December 2018):32-4.

13. Mekitarian Filho Eduardo. Is dexmedetomidine the gold standard for pediatric procedural sedation and anxiolysis?. Rev. Assoc. Med. Bras. [Internet]. $2017 \quad$ Apr [cited 2020 Sep 30]; 63(4): 299-300. Available from: http://www.scielo.br/scielo.php?script=sci_ arttext\&pid $=$ S0104-
42302017000400299\&Ing=en. http://dx. doi.org/10.1590/1806-9282.63.04.299.

14. Kilicaslan, Alper \& Erol, Atilla \& Uzun, Sema. (2014). Comparison of the C-MAC D-Blade, Conventional C-MAC, and Macintosh Laryngoscopes in Simulated Easy and Difficult Airways. Turkish Journal of Anesthesia and Reanimation. 42. 182-189. 10.5152/TJAR.2014.59672. 